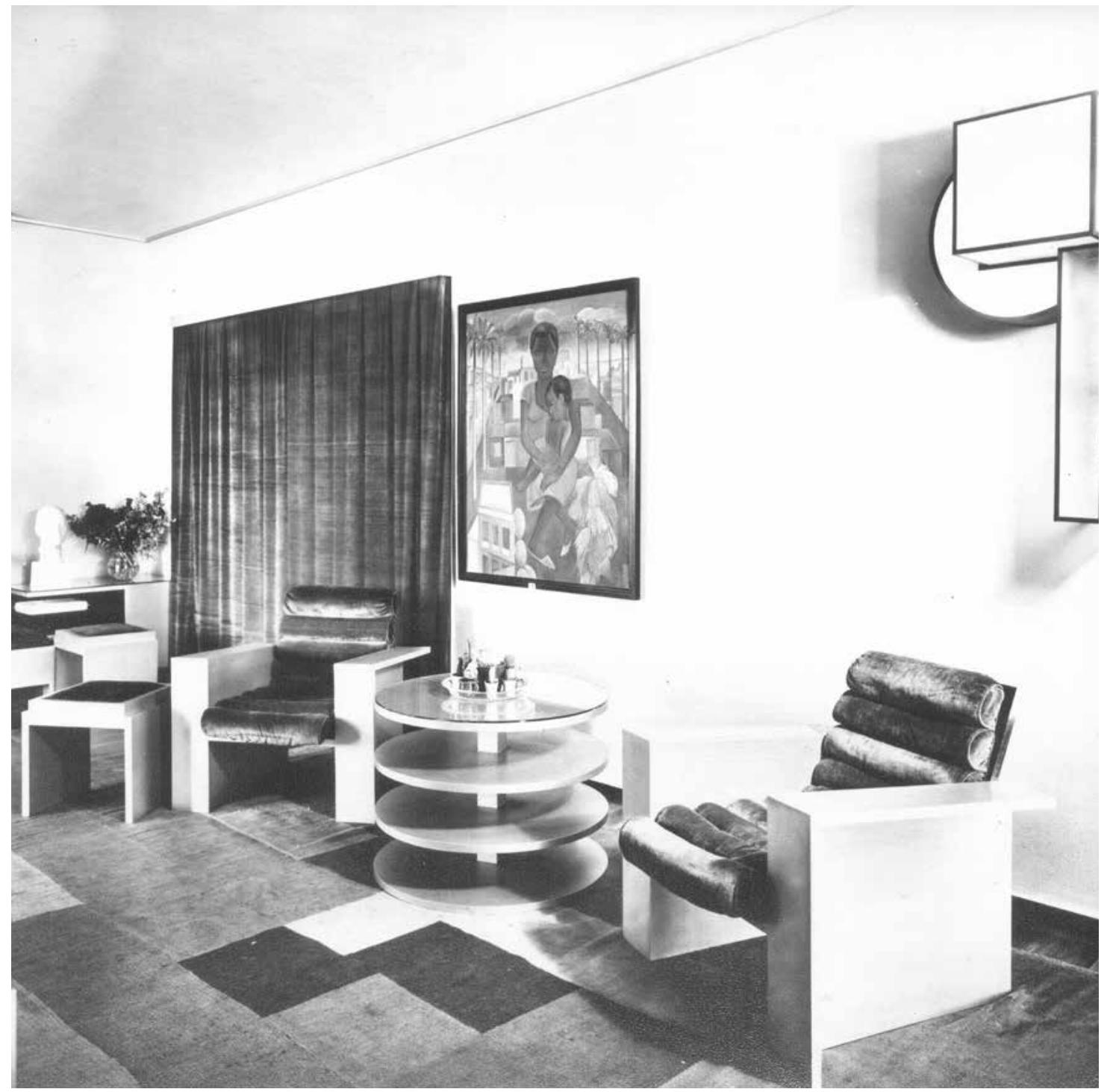


ano 10

n 20

palavras-chave: Gregori Warchavchik; mobiliário; modernismo;

Casa Modernista

keywords: Gregori Warchavchik; furniture; modernism; Modernist House

Artigo recebido em 03 de agosto de 2012 e aprovado em 17 de outubro de 2012

Gregori Warchavchik. Móveis feitos para o interior da Casa Modernista, 1930. Foto gentilmente cedida por Adolpho Leirner.

\section{Anatomia de um Móvel Moderno: algumas questões em torno do Mobiliário da Casa Modernista, de Gregori Warchavchik ${ }^{1}$}

A afirmação da estética modernista no Brasil perpassa diversas práticas artísticas, entre elas o da decoração de interiores. De um modo geral, o protagonismo na introdução do design modernista no Brasil é atribuído ao suíço John Graz e ao ucraniano Gregori Warchavchik, dois imigrantes aportados no país em inícios da década de $1920^{2}$. Sem contestar o papel que ambos desempenharam para a promoção de uma atualização do design de interiores, o presente artigo pretende analisar o mobiliário concebido por Gregori Warchavchik para a Casa Modernista procurando mostrar que esse, em sua materialidade, apresenta contradições que transparecem os impasses então vivenciados entre um certo ideário modernista almejado e as práticas concretas possíveis para sua realização na cidade de São Paulo em inícios do século XX.

The affirmation of the modernist aesthetics in Brazil involves various artistic practices, including the decoration of interiors. In general, the protagonism in the introduction of modernist design in Brazil is attributed to the swiss artist John Graz and the ukrainian architect Gregori Warchavchik, two immigrants that have contributed artistic field in the 1920s. Without denying the role of the both to promote and update the interior design in Brazil, this article analyzes the furniture design made by Gregori Warchavchik to the Modernist House of 1930, trying to show that, in its materiality, presents contradictions that are apparent deadlocks then experienced between a certain modernist ideals pursued, and concrete practices possible for its realization in the city of Sao Paulo in the early twentieth century. 
Anatomia de um Móvel

Moderno: algumas questões em torno

Em 1923, o arquiteto ucraniano Gregori Warchavchik desembarcava do Mobiliário da Casa Modernista, de Gregori em São Paulo, após ter se formado no célebre Instituto Superior de Belas-Artes de Roma, portando cartas de recomendação para atuar profissionalmente na Companhia Construtora de Santos, pertencente a Roberto Simonsen. Apenas dois anos depois, em 1925, Warchavchik lança-se no campo local afirmando-se como um "precursor" da arquitetura moderna no Brasil, por meio da publicação do artigo "Intorno all'architettura moderna”, sob a rubrica "Il futurismo", na coluna de arte do jornal paulistano Il Piccolo. Em novembro daquele mesmo ano, o artigo saía publicado em português, no Correio da Manhã do Rio de Janeiro, mostrando a sua relativa repercussão ${ }^{3}$.

O texto é considerado o primeiro manifesto a favor da arquitetura modernista publicado no país ${ }^{4}$. Segundo José Tavares Correia de Lira, especialista na produção e trajetória do arquiteto, propunha de um lado "repensar a edificação tradicional a partir da racionalidade interna de seus atributos técnicos e decorativos"; de outro, reconhecer as exigências impostas pelo desenvolvimento da indústria em uma "época de capitalismo incipiente, onde a questão da economia predomina sobre todas as demais”. A defesa da racionalidade construtiva passava, naquele momento, pela recusa absoluta ao ornamento e da reivindicação da economia construtiva, com isso afastando-se deliberadamente das correntes historicistas e ecléticas que dominavam o panorama arquitetônico local.

Um outro passo significativo para a afirmação do modernismo arquitetônico em São Paulo é efetivado pelo arquiteto em 1930. Trata-se da construção da emblemática Casa Modernista, localizada na rua Itápolis, no bairro do Pacaembu, em São Paulo. No dia 24 de março daquele ano, a casa foi aberta à visitação do público, estampando o caráter de obra exemplar com que fora concebida pelo arquiteto. Essa havia sido pensada como uma obra de arte única, na qual todas as partes estariam integradas por intermédio de linguagens harmônicas, revelando uma concepção de design incomum na capital paulista de então. A fachada, a estrutura da casa, a decoração interna - inclusive o mobiliário, as cortinas, os tapetes, as portas, as luminárias - e até mesmo sua parte externa, comportando o jardim, foram planejados em diálogo com os partidos estéticos modernistas, mormente de tipo funcionalista. Isso demandou uma atuação polivalente da parte do arquiteto, que, além de desenhar e acompanhar a

\section{0 presente artigo é uma versão desenvolvida do texto apresentado no $35^{\circ}$ Encontro Anual da ANPOCS, dentro do Fórum intitulado: Imagens, arte e novas tecnologias: a atualidade da pesquisa em ciências sociais, realizado em Caxambu, em 2011. \\ 2. A esse respeito consultar o livro de referência sobre o assunto: DOS SANTOS, Maria Cecilia Loschiavo. 0 móvel moderno no Brasil. São Paulo: Studio Nobel/EDUSP, 1995. Especificamente sobre a atuação de John Graz, ler: AFONSO, Anna Maria. John Graz: o arquiteto de interiores. Dissertação (Mestrado em Fundamentos da Arquitetura e do Urbanismol, Faculdade de Arquitetura e Urbanismo, Universidade de São Paulo, 2008.}

3. Sobre a trajetória de Gregori Warchavchik e sua produção como arquiteto e teórico consultar o livro de LIRA, José Tavares C.

Gregori Warchavchik. Fraturas da vanguarda. São Paulo: Cossac \& Naify, 2011. Muitos dos argumentos aqui mobilizados dialogam diretamente com o livro em questão que é a pesquisa mais minuciosa e bem 
construção da casa, planejou e produziu toda a decoração interior, como os móveis, as peças de iluminação, as portas e janelas. Seguindo uma divi-

fundamentada já feita sobre o arquiteto "Gregori Warchavchik:combates pelo futuro", In: WARCHAVCHIK, G. Arquitetura do século $X X e$ outros escritos. São Paulo: Cossac \& Naify, 2006.

4. Sobre o lugar de Warchavchick na historiografia da arquitetura brasileira consultar: MARTINS, Carlos Ferreira.

5. Sobre a produção de Minna Klabin Warchavchik ler: PERECIN, Tatiana.

Azaléias e mandacarus. Mina Klabin Warchavchik, paisagismo e modernismo no Brasil. Dissertação de mestrado em Arquitetura e

Urbanismo, EESC-USP, 2003. É interessante notar que diversos casais de artistas realizaram projetos decorativos coletivos, nesses geralmente, os homens eram incumbidos de realizarem as partes mais importantes como o projeto (a concepção total), o mobiliário, as luminárias etc, ao passo que as mulheres ocupavam-se dos gêneros vistos como inferiores, como os têxteis, ou jardinagem. Isso ocorre, por exemplo, com outra dupla importante de artistas-decoradores no Brasil: John e Regina Graz. A esse respeito são do trabalho comum aos circuitos modernistas, o jardim ficou a cargo de sua esposa, Minna Klabin Warchavchik 5 .

A residência erguia-se como uma obra de arte total. A arquitetura funcionando como uma moldura, preenchida por um conjunto significativo de obras modernistas, como um bronze de Lipshcitz, almofadas de Sonia Delaunay e Dominique, um tapete da Bauhaus, molduras de Pierre Legrain. Tais peças, pertencentes a coleções brasileiras, ombreavam-se com os exemplares modernistas nacionais: quadros, esculturas e gravuras de Segall, Gomide, Di Cavalcanti, Cícero Dias, Anita Malfatti, Celso Antonio, Brecheret, Goeldi, Jenny Klabin Segall, e ainda almofadas de Regina Graz, um baixo-relevo de John Graz e peças do próprio Warchavchik estavam ali reunidos, numa comunhão de linguagens modernas ${ }^{6}$.

A própria concepção de uma casa como uma totalidade integrada de obras decorativas de linguagens interdependentes estampava como o arquiteto estava atinado com experiências internacionais do mesmo gênero levadas a cabo por arquitetos decoradores ao longo dos anos 1920 na Europa, entre eles Mallet-Stevens, Djo-Bourgeois, Rulhmann, Eileen Gray e, particularmente, Le Corbusier, que, em parceria com Charlotte Perriand, criou unidades domésticas formalmente integradas a partir das premissas de racionalidade, simplicidade, utilidade, economia e higiene, compreendendo desde a fachada até os elementos mínimos de seu interior, ao que denominavam "machine à habiter" .

Naquele contexto, é importante destacar que o mobiliário havia se tornado um elemento fundamental para uma concepção moderna de residência, a ponto de praticamente todos os grandes arquitetos do período terem se aventurado também em projetos decorativos, criando móveis específicos para os interiores que concebiam ${ }^{8}$. Warchavchik participou de tal processo, e assim como seus contemporâneos, partidários do credo modernista, considerava uma excrescência a utilização de móveis de época dentro de ambientes modernos. Preocupação que se evidencia no mencionado artigo de 1925 quando indaga:

"Encontrarão nossos filhos a mesma harmonia entre os últimos tipos de automóveis e aeroplanos de um lado e a arquitetura de nossas casas de outro? Não, esta harmonia não poderá existir enquanto o homem moderno continue a sentar-se em Salões Luis tal ou em salas de jantar estilo Renascença e não ponha de lado os velhos métodos de decoração das construções". 
O texto afirma que a busca pela harmonia entre a cultura e a resi-

ANA PAULA SIMIONI

Anatomia de um Móvel Moderno: algumas questões em torno do Mobiliário da Casa Modernista, de Gregori Warchavchik

consultar: SIMIONI, Ana Paula C. Regina Gomide Graz: modernismo, arte têxtil e relações de gênero no Brasil. In: Rev. Inst. Estud. Bras. [online]. 2007, n.45, p. 87-106.

6. A esse respeito, ler LIRA, Op. cit., especificamente 0 capítulo 7, Uma casa em exposição.

7. OZENFANT e JEANNERET [Le Corbusier]. A situação atual da vida moderna, In: MARTINS, Carlos F. (org). Depois do cubismo. São Paulo: Cossac \& Naify, 2005.

deira revela um dos aspectos mais interessantes, e contraditórios, de tal mobiliário $^{11}$. O uso da pigmentação denota o desejo de obter um efeito específico: aparentar ser um móvel metálico. A questão do material a ser empregue não é um detalhe, mas bem ao contrário, trata-se de um elemento crucial nos debates estéticos em vigor naquele momento. Elemento do qual Warchavchik era plenamente consciente já em 1925, a ponto de concluir seu eminente manifesto com a seguinte sentença:

"O arquiteto moderno deve amar sua época, com todas as suas grandes manifestações do espírito humano, como a arte do pintor moderno ou poeta moderno deve conhecer a vida de todas as camadas da sociedade.

Tomando por base o material de construção de que dispomos, estudando-o e conhecendo-o como os velhos mestres conheciam sua pedra, não receando exibi-lo no seu melhro aspecto do ponto de vista da estética, fazendo refletir em suas obras as ideias do nosso tempo, a nossa lógica[....].

Abaixo as decorações absurdas e viva a construção lógica, eis a divisa que deve ser adotada pelo arquiteto moderno" ${ }^{12}$.
8. A esse respeito consultar: BENTON, Charlotte. Le Corbusier: Furniture and the Interior, In: Journal of Design History, Oxford, vol, n²/3, 1990.

9. Warchavchik, G. Acerca da arquitetura moderna. In: Arquitetura do século $X X$ e outros escritos, Op. cit., p.35-6. Originalmente publicado sob o título "Futurismo" no jornal II Piccolo, São Paulo, 14 jun. 1925, e depois traduzido como Acerca da arquitetura moderna, no Correio da Manhã, 1 nov. 1925.

10. Idem, Ibidem, p. 37. 
O lema modernista da busca pelos materiais adequados ao presente, os quais deveriam ser utilizados de modo visível nas construções, evitando seu

11. Sophia Telles já havia percebido a contradição de tal mobiliário. TELLES Sophia. A arquitetura modernista, um espaço sem lugar. In: TOLIPAN, Sergio.

Sete ensaios sobre 0 modernismo. Rio de Janeiro: FUNARTE, 1983.

12. Idem, Ibidem, p. 37-8. Grifos meus.

13. Consultar: BAYER, Patricia. Intérieurs

Art Déco. Thames and Hudson, 2007.

Charlotte Perriand. Le Bar sous le toile. Obra apresentada ao Salon D’Automne. Art et Décoration, Paris, déc. 1927, p. 173.

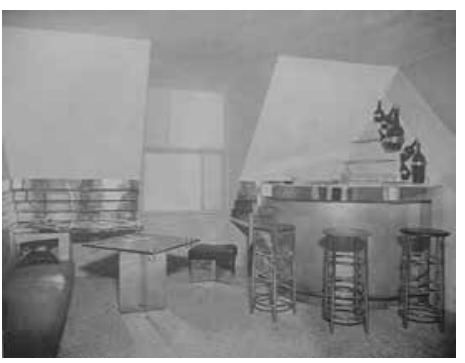
camuflamento por meio de elementos acessórios ou decorativos, traduzido em outro lema modernista conhecido como a "verdade dos materiais", encontrara no mobiliário de Warchavchik uma contradição muito significativa.

\section{Disputas pelo móvel "moderno" no campo do design internacional, década de 20:}

A produção do conjunto de móveis para a Casa Modernista não pode ser plenamente compreendida fora do debate internacional. Ao longo da década de 1920 travou-se uma real batalha entre os designers de interiores, na época denominados artistas-decoradores, sobre os usos e significados dos materiais utilizados pela moderna arquitetura. Nas páginas da revista francesa Art et Décoration, um dos mais importantes periódicos dedicados às artes decorativas desse momento, é possível acompanhar tal celeuma. O campo das artes decorativas vivenciava uma grande proliferação de estilos, tendências, debates e disputas acirradas entre grupos ${ }^{13}$. $\mathrm{Na}$ ocasião do afamada Exposition des Arts Decoratifs de 1925, a partir da qual se disseminou a expressão "art déco", a crítica especializada já percebia com clareza a existência de ao menos duas orientações distintas - e antagônicas - para os novos rumos das artes aplicadas, por um lado os artistas denominados como modernos e, por outro, os contemporâneos:

"[...] A ebenesteria moderna rejeita o ornamento. Esse é seu traço específico. Será, porém, seu traço distintivo? A arte dos Emile Ruhlmann, de André Groult, de Süe e Mare, não é ela moderna? $[\ldots]$

Não se saberia com mais bondade, inteligência e habilidade ligar o passado ao presente e renovar a tradição: Louis Süe e André Mare se apegam às formulas da Restauração, Groult àquelas do século XVIII e Ruhlmann às do Império [...]. Eles próprios, aliás, declinam quanto à qualificação de artistas 'modernos'. Eles são 'contemporâneos'. Emile Ruhlmann cria móveis 'contemporâneos'. É no 'Museu de Arte Contemporânea' que se dispõe Süe e Mare na exposição que se abre.

'Contemporâneo' e não 'moderno': constatação de um estado de fato, mas não de profissão de uma doutrina. Quem diz 'moderno' define, com efeito, uma estética. [....] São os recursos técnicos atuais, as condições econômicas e domésticas presentes que os seduzem. Com efeito, nossa preocupação com a higiene, nosso gosto pelos esportes, nosso cientificismo não atribuem ao banheiro uma importância determinante? Nós criamos para ela, como consequ- 
ência, um mobiliário inteiramente novo. São móveis estabelecidos para uma sociedade apressada, privada de servidores, mas que, sobretudo, ama a ordem e o método, essa higiene do espírito" ${ }^{14}$.

O texto assinado pelo crítico Guillaume Janneau (1887-1968) identificava duas perspectivas predominantes no salão. De um lado, artistas-decoradores dedicados a recuperar elementos daquilo que aponta como a "tradição nacional francesa" e readequá-los às demandas do presente, o que implicava manter a sofisticada cultura ebanista secular do país, adaptando-a para os novos usos, funções, espaços e gostos; a esses nomeava contemporâneos. Dentre eles destacava os nomes de Emile Ruhlmann, Louis Sue, André Mare, Grouault. De outro lado, um grupo de jovens artistas ansioso justamente por romper com o passado, instaurando uma estética calcada na funcionalidade, livre de quaisquer tipos de ornamentações, elementos esses constantemente acusados nos discursos de serem historicistas, fúteis e atrelados a um tempo que deveria ser superado ${ }^{15}$. Para tanto, defendiam que o mobiliário deveria utilizar-se de materiais novos, compassados ao mundo do presente, então associado ao universo das indústrias, da ciência, do trabalho, do movimento, da higiene. Tal grupo era denominado como os modernos, dentre os quais se contava a participação de Le Corbusier, Charlote Perriand, Mallet Stevens, Djo-Borjouis, entre outros.

A disputa entre modernos e contemporâneos foi intensa e constante ao longo de toda a década de 1920, fazendo-se notar nas exposições, nos salões e na crítica. A questão dos materiais adequados ao mobiliário ocupava um papel crucial na divisão de grupos e orientações. Já em 1925, na exposição anual do Salon des Artistes Décorateurs, a mais afamada mostra internacional de artes decorativas, o uso do metal no mobiliário despontou como um emblema de modernidade. Inicialmente utilizado apenas em algumas partes dos móveis, como nos pés ou nas maçanetas, a fim de prover estruturas mais resistentes ao uso, aos poucos se tornando um elemento compositivo central.

Comentando o Salão de 1927, o crítico Leon Deshairs detém-se particularmente sobre os móveis de E. Ruhlmann, artista exemplar da tendência anteriormente descrita como "contemporânea" por seu esmero técnico na renovação da tradição ebanistíca, no uso de materiais requintados e exclusivos. Mesmo esse partidário do diálogo com a tradição, aos

\section{ANA PAULA SIMIONI}

Anatomia de um Móvel

Moderno: algumas questões em torno do Mobiliário da Casa Modernista, de Gregori Warchavchik

14. JANNEAU,

Guillaume. Introduction a L'Exposition des Arts Décoratifs: Considerations sur l'Esprit Moderne. In: Art et Décoration, maio, 1925, p. 149150. No original: “ [...] l'ébénisterie moderne rejette l'ornement. C'est meme lá son trait spécifique. Est-ce toutefois son trait distinctif? L'art des Emile Ruhlmann, des André Groult, des Süe et Mare, n'est-il pas moderne? [...] On ne saurait avec plus de bonheur, $d$ 'intelligence et d'habilité, relier au passé le present et renouer la tradition: Louis Süe et André Mare se rattachant aux formulas de la Restauration, Groult à celles du dix-huitième siècle et Ruhlmann à celles de l'Empire [...]. Eux-mêmes, d'ailleurs, déclinent la qualification d'artites 'modernes'. Ils sont 'contemporains'. Emile Ruhlmann crée des meubles 'contemporains'. C'est le "Musée d'art contemporain' qu'aménagent Süe et Mare à l'exposition qui s'ouvre. Contemporain', non 'moderne': constatation d'un état de fait, mais non profession d'une doctrine. Qui dit 'moderne' définit, en effet, une esthéthique. [...] C'est des ressources techniques actuelles, 
poucos incorpora materiais novos como o metal em seu trabalho, o que é visto como um "progresso". O próprio título do artigo "Uma etapa rumo ao móvel metálico", deixa claro o quanto o móvel de metal era visto como um devir obrigatório:

et des conditions économiques et domestiques presents qu'ils les déduisent. En effet, notre souci $d$ 'hygiène, noutre goût des sports, et notre scientificisme n'accordent-ils pas à la sale de bains une importance déterminante? On crée pour elle, en consequence, un mobilier tout nouveau

(...) Ce sont lá des meubles établis pour une société pressée, privée de serviteurs, mais qui,surtout, aime l'order et la méthode, cette hygiene de l'esprit [...]". Tradução da autora.

15. Tais posturas encontram-se representadas em textos modernistas programáticos fundamentais, tais como: LOOS, Adolf. Ornament und Verbrechen (1908), trad. portuguesa Ornamento e crime. Lisboa: Cotovia, 2006; LE CORBUSIER, L'art decoratif d'aujourd'hui (1925), trad. portuguesa,

A arte decorativa de hoje. São Paulo: Martins Fontes, 1996.

16. DESHAIRS, Leon. Une étape vers le meuble métalique. In: Art et Décoration, Paris, abril de 1927,
"Nos vagões, nos automóveis, o metal progressivamente eliminou a madeira. Deve ele também estar, um dia mais ou menos longínquo, dentro do mobiliário da casa? Veremos nós móveis inteiramente metálicos, ou ao menos, nos quais a madeira, quente, colorida, com qualidades inigualáveis não intervirá apenas como adorno? Aguardemos a profecia. Mas, do ponto de vista da resistência às mudanças da temperatura, os autores dos móveis reproduzidos nessas páginas atingiram suas metas. E, do ponto de vista estético, suas experiências provam que, mesmo num escritório de trabalho, ou num quarto, o metal e a madeira fazem uma boa parceria. Que se marque ou não uma etapa rumo ao móvel inteiramente metálico, os móveis semi-metálicos de Ruhlmann e de Chareau acusam um novo progresso do móvel metálico" ${ }^{16}$.

O ano de 1927 evidencia o triunfo dos móveis em metal no Salão, tornando-se mesmo o principal assunto da mostra. Dentre os artistas decoradores designados como contemporâneos o metal é utilizado ao lado da madeira, que continua a ser o elemento predominante, tal como nos exemplares projetados por Ruhlman. Mas dentre os modernos cada vez mais nota-se um esforço em transformar o metal no material predominante no mobiliário. Particularmente importante no campo francês da decoração deste momento é o conjunto proposto por Charlotte Perriand para um bar, posto que se trata de um projeto inteiramente feito em metal, destacando-se bastante no Salão daquele ano, tal como se percebe no destaque obtido na prestigiosa publicação.

É fundamental também lembrar que a afirmação do móvel metálico não ocorria apenas na França ${ }^{17}$. Na verdade, o pioneirismo deve ser atribuído às produções de Marcel Breuer, desenvolvidas em Dessau, na Alemanha, no interior da prestigiosa escola de Bauhaus. Em 1925 este já havia concebido uma cadeira inteiramente feita em tubos de aço,a Cadeira Club, posteriormente denominada como "Vassily". Os móveis concebidos por Breuer tiveram sucesso imediato, dentro e fora da escola, Gropius convidara-o para mobiliar todo o edifício da escola. E, já no ano seguinte, os móveis por ele concebidos já encontravam uma aplicação industrial, por meio da empresa Standar-Möbel fundada por ele e Kálmán Lengyel. Em 1927, Breuer assinava um contrato com a empresa Thonet, uma mar- 
ca emblemática no ramo do mobiliário internacional desde o século XIX,

ANA PAULA SIMIONI e passava a desenhar para ela uma série de peças em aço tubular, como a Cadeira Cantilever. Com efeito, o mobiliário em metal elaborado por Breuer foi fundamental para a própria constituição e projeção de imagem de modernidade propagada pela Bauhaus ${ }^{18}$.

O significado do uso do metal transcendia a sua mera aplicabilidade técnica, possuindo um profundo sentido cultural aos olhos de seus defensores. Era então alçado à condição de material emblematicamente moderno: adaptado à civilização mecânica, à era das máquinas e do trabalho, higiênico, resistente, funcional, limpo e prático, símbolo de modernidade. Além do mais, trazia consigo a possibilidade de uma produção industrializada para consumo de grande público. Com isso, o uso do aço tubular paulatinamente tornou-se sinônimo de estética modernista, ao passo que a utilização da madeira associou-se, naquele decênio, à prática dos artistas tidos como contemporâneos, termo que, diferentemente de seu sentido atual, agrupava artistas de orientação mais tradicional. Cada um desses meios era então impregnado de simbologias; o metal representava o primado da funcionalidade, do presente e do futuro. Já a madeira adquiria um sentido oposto, o de sofisticação, de artesania, de apego às tradições, em suma, era entendido como a materialização do apego ao passado ${ }^{19}$.

Todavia, é importante lembrar que tais discursos faziam questão de negligenciar certos pontos. Primeiramente, o fato de que havia sido Ruhlmann o introdutor do metal em seus trabalhos, em pequenos detalhes como os pés e maçanetas, antes de os designados "modernos" o fazerem. Em segundo lugar, que o custo de tal material era tamanho que tornava seu consumo altamente elitizado, contrariando o princípio democrático perseguido pelos modernistas. Com efeito, muito da produção dos modernistas realizada na França não contou com uma aplicação industrial, como ocorrera na Alemanha com as obras de Breuer, possuindo assim um caráter muito mais de projeto, de modelo do que propriamente de objetos de consumo. E, em terceiro lugar, a partir dos anos de 1930 percebe-se uma tendência geral, compartilhada por ambos os lados, em optar pela madeira como material preponderante, em um movimento que pode ser compreendido como o de "volta ao homem", como bem definiu Romy Golan. Segundo a autora, evidencia-se durante a década de 1930 uma tendência geral mais conservadora na produção cultural francesa, incluindo o campo do mobiliário. Ruhlmann, por exemplo, abole o polimento da superfície, que era então uma de suas marcas, a fim de salientar o aspecto
Anatomia de um Móvel

Moderno: algumas questões em torno do Mobiliário da Casa Modernista, de Gregori Warchavchik

p. 110. No original: "Dans les wagons, les autos, le metal a progressivement éliminé le bois. Doit-il en être de même, um jour plus ou moins lointain, dans le mobilier de la Maison? Verrons-nous des meubles entièrement métalliques, ou du moins ou le bois, chaud, colore, aux qualités sans égales, $n$ 'interviendra plus que comme garniture? Gardons-nous de jour au prophète. Mais, au point de vue de la résistance aux changements de température, les auteurs des meubles reproduits en ces pages ont atteint leur but. Et, au point de vue esthétique, leur expérience a prouvé que, même dasn um cabinet de travail ou une chambre, metal et bois peuvent faire bon ménage. Qu'ils marquent ou non une étape vers le meuble entièrement metallique, les meubles semimétalliques de Ruhlmann et de Chareau accusent un nouveau progrès du meuble moderne". Tradução da autora.

17. Sobre a história da técnica do mobiliário em metal, consultar: Tubular Steel Furniture: Antecedents and Early History, In: Journal of Design History, Oxford, vol 3. N.2/3. 1990. 
mais 'natural' da madeira, mostrando a busca de um diálogo com a tradi-

18. COBBES, Arnt.

Marcel Breuer, 1902-1981.Criador da forma do século $X X$. Koln: Taschen, 2009, p.

21. Para uma análise densa sobre o designer e sua produção ler: ARGAN, Giulio Carlo.

Marcel Breuer- desenho industrial e arquitetura.

In: Arte moderna na

Europa, de Hogarth

a Picasso. São Paulo:

Companhia das Letras,

2010.

19. A esse respeito consultar: GOLAN,

Romy. Modernity and Nostalgia: Art and Politics in France between the Wars. New Haven, London, Yale University Press, 1995.

20. GOLAN, Romy, Op. cit. Sobre o retorno de Perriand aos materiais tradicionais, ler Benton, Op cit. Sobre Perriand, ler também: RUBINO, Silvana. Corpos, cadeiras, colares:

Charlotte Perriand e Lina Bo Bardi. Cadernos Pagu [online]. 2010, n.34, p. 331-362.

21. Léon Werth (18781955) foi um importante crítico de arte e de política, além de ensaísta e novelista. Era próximo a Octave Mirabeau, além de Saint-Exupery, que the dedica seu sentido político, o de demonstrar o apreço pela "antiga França”, que havia resistido bravamente aos impactos da I Guerra. De outro lado, Charlotte Perriand que, nos anos 1920 havia redigido manifestos programáticos contra a madeira e realizado obras paradigmáticas, como o bar de 1927, nos anos de 1930 passa a realizar obras em que opta pelo uso abundante do material outrora negado, defendendo-o dessa vez como mais "adequado à esfera humana”. Matizando sua posição anterior integralmente simpática aos princípios revolucionários dos "modernistas”, nos escritos da década de 1930 a artista-decoradora passou a defender o uso de elementos associados ao vernáculo, e mesmo a assimilar influências "regionais"20.

No entanto, em finais dos anos de 1920, essa volta à tradição ainda era vista com muitas reservas pelos modernistas, antes bem ao contrário, trata-se de um momento de euforia para com os elementos constitutivos da "civilização do presente". O artigo assinado por Leon Werth ${ }^{21}$ na revista Art et Décoration é esclarecedor dos sentido cultural que os materiais adquiriram, notadamente no que tange à crença no metal como um elemento de afirmação da sociedade do presente, e do futuro:

"E é aqui que Ruhlmann nos convida à antecipação, Ruhlmann que prefere costumeiramente nos seduzir somente pela perfeição e aristocracia de seu gosto. Ele expõe um móvel metálico (um ensaio sobre um móvel de aço). Léon Deshair demonstrou aqui mesmo o conflito entre nosso apego ao 'calor da madeira' e as esperanças que o metal e a mecânica sugerem ao nosso espírito. Nós vivemos uma idade do metal. Sem que seja mesmo necessário se fazer intervir considerações utilitárias, e pouco sedutoras que possam ser a matéria, o metal, em nossa época de maquinismo, exerce uma atração sobre nós. Nós queremos móveis estritos como as carrocerias. [...] móveis perfeitamente adaptados a uma civilização mecânica e a um universo desmadeirizado" 22 .

III. A forma possível: os sentidos das contradições do mobiliário da Casa Modernista

É muito provável que Warchavchik conhecesse tal debate por intermédio das revistas ilustradas comercializadas mundialmente que aportavam no Brasil ${ }^{23}$. Nesse sentido, realizar um conjunto de móveis adaptado ao ideal de uma casa modernista era um objetivo programático. Afinal, 
como nota Charlotte Benton, o design do móvel moderno alçara a condição de alegoria exemplar do próprio modernismo ${ }^{24}$. Desse ponto de vista, a concretização do móvel plenamente adaptado ao seu tempo significava uma aproximação com as propostas mais vanguardistas, que defendiam a eliminação do historicismo, do ornamento, a reprodutibilidade industrial e, finalmente, o uso obrigatório do metal.

Todavia, apesar do "efeito" obtido pela tinta prateada aproximar visualmente o móvel das produções que Warchavchik considerava inovadoras, a estrutura é toda de madeira, material desvalorizado pela crítica modernista internacional por ser tradicional, pesado, caro, nobre, inapropriado aos tempos de predomínio de uma civilização técnica. A primeira vista o móvel parece uma realização primeira, pioneira, do móvel moderno no Brasil por conta de seu absoluto despojamento formal, calcado em um claro rigor geométrico, em uma ostensiva recusa ao ornamento, bem como em seu aspecto metálico. Todavia, como compreender as sugestivas contradições intrínsecas ao objeto? Nele, a luminosidade prateada não advém de uma base metálica, como seria de se esperar, mas sim de uma tinta que imitaria o almejado material, sob a qual o arquiteto escondia, disfarçava mesmo, sua base real: a madeira. Ao "maquiar" seu objeto, Warchavchik rompia com mais um mandamento do ideário modernista, a saber, o de salientar a verdade dos materiais.

$\mathrm{O}$ arquiteto era extremamente consciente da importância que os materiais haviam adquirido para as práticas modernistas, não apenas no que tange aos princípios construtivos observados, mas em sua explicitação. Um dos elementos que os diferenciava enquanto grupo era, justamente, o não ocultamento dos materiais construtivos por intermédio do uso de fachadas, ornamentos, coberturas, práticas associadas aos "passadistas", nome dado aos caudatários dos princípios ecléticos. Nesse sentido, afirma Warchavchik:

"Pouco tempo passará, e não se poderá mais falar de estilo gótico, Renascimento, Luís XV e outros sem parecer ridículo, salvo referindo-se ao passado.

Haverá um só estilo moderno, com as suas diferenças oriundas do clima e dos costumes. Teremos talvez uma arquitetura européia, outra sul-americana, outra americana. Finalmente todas juntas formarão um só estilo mundial, criado pelas mesmas exigências da vida, pelo material idêntico usado para a construção, o concreto, o ferro, o vidro [....]. O arquiteto do futuro não copiará coisa alguma. Procurará inspirar-se no material, do qual usará sempre o mais no-
ANA PAULA SIMIONI

Anatomia de um Móvel Moderno: algumas questões em torno do Mobiliário da Casa Modernista, de Gregori Warchavchik

mais conhecido livro "0 Pequeno Príncipe", de orientação anarquista, publicou textos e livros contra a colaboração Francesa ao III Reich, durante a Segunda Guerra Mundial.

22. WERTH, Leon. Le Salon des Artistes Décorateurs. In: Art et Décoration, Paris, numèro exceptionel, junho de 1927, p. 168. No original: Et c'est ici Ruhlmann que nous convie à l'anticipation, Ruhlmann qui prefere $d$ 'ordinnaire nous séduire par la seule perfection et la seule aristocratie de son goût. Il expose um meuble métallique lessai sur le meuble d'acier). Léon Deshairs a montré ici même le conflit entre notre attachement à la 'chaleur du bois' et les espérances que le metal et la mécanique suggèrent à notre esprit. Nous vivons un âge du metal. Sans même qu íl soit nécessaire de faire intervenir des considérations utilitaires, et si peu séduisante qu'en puísse être la matière, le metal, en notre époque de machinisme, exerce une attraction sur nous. Nous voulons des meubles stricts comme des carrosseries. [...] du meuble parfaitement 
bre possível, estudará os arredores imediatos e as exigências da vida

ano 10

n 20 particular dos futuros habitantes. Assim as construções terão caráter original, fomar-se-á um estilo novo, próprio ao lugar, confortável e de absoluta beleza" ${ }^{25}$.

adapte à une civilisation mécanique et à um Univers déboisé.". Tradução da autora.

23. Infelizmente não se conhece o paradeiro da biblioteca do arquiteto, no entanto, sabe-se que revistas modernistas importantes como a Esprit

Nouveau, a Deutsche Kunst um Dekoration, a The Studio, a Cahiers d'Art entre outras, eram lidas no Brasil, discutidas entre os grupos dos quais Warchavchik fazia parte. A esse respeito: LIRA, Op. cit., p. 143; CAPPELLO, Maria Beatriz. Arquitetura em revista: arquitetura moderna no Brasil e sua recepção nas revistas francesas, inglesas e italianas. São Paulo, Tese de Doutorado, Faculdade de Arquitetura e Urbanismo-USP, 2006; CARVALHO, Lilian Escorel de. A revista francesa L'esprit Noveau na formação das ideias estéticas e da poética de Mário de Andrade. São Paulo, Tese de Doutorado em Literatura Brasileira,

Universidade de São Paulo, 2008.

24. Diz a autora: "The design of the modern chair thus became a kind of exemplary allegory of modernism. The modern man and woman needed
Os materiais do presente (ferro, vidro, concreto) são tomados como a base de um princípio universalmente compartilhado. O mobiliário em questão revela justamente as distâncias existentes entre o desejo de uma estética moderna internacionalmente difundida pelos modernistas e as possibilidades concretas, reais, com que o designer brasileiro contava. Tal questão já foi analisada por Carlos Lemos, em 1983, referindo-se aos projetos arquitetônicos, de sorte a apontar a incongruência entre a dimensão publicista de Warchavchik e sua prática como construtor, particularmente no caso da residência da Vila Marina. Segundo o autor:

"[...] Foi sua primeira tentativa de arquitetura moderna, infelizmente, a nosso ver, sem validade, porque se ateve somente aos aspectos formais. A técnica construtiva empregada foi a tradicional dos muros contínuos de alvenaria de tijolos, não usando o já vigente concreto armado, não fazendo o esperado terraço jardim, cobrindo a casa com telhas comuns de barro logo escamoteadas. [...] Percebe-se, nesse raciocínio, que ele transformava um edifício tradicional em 'moderno' com a simples eliminação de molduras e ornatos. Esse comportamento leva-nos a pensar que o arquiteto entendia mais a modernidade arquitetônica como um 'estilo' do que uma postura perante os recursos e pensamentos contemporâneos. Pudemos ver casa de plantas semelhantes e de mesma volumetria vestidas de roupagem neoclássica, arte-nouveau (sic) ou neocolonial, segundo o desejo do proprietário e, na verdade, podemos dizer que a casa da Vila Mariana era também uma casa tradicional, porém 'despida' e, por isso, 'moderna”'26.

Também José Lira analisa a distância entre as práticas construtivas mobilizadas e os ideais modernistas defendidos por Warchavchik, notadamente na Casa da Rua Santa Cruz, mas ao invés de condená-la, de ver nas incongruências sinais do fracasso do arquiteto, de sua limitação estética ou de sua adesão incompleta ao credo modernista, se propõe a tirar partido da contradição, pois como afirma o autor:

"[...] a casa da rua Santa Cruz, porque contraditória, é a obra mais emblemática da virada arquitetônica brasileira. Urbana e suburbana, moderna e clássica, inovadora e convencional, provinciana e cosmopolita, a casa representa eloquentes matrizes compositivas e, simultaneamente, a negação de todos os estilos. [....] As discrepâncias visuais, concessões e desvios patentes em sua arquiteutra, em vez de atestarem uma defasagem, aludem às 
possibilidades concretas do modernismo no solo social e cultural específico em que se exprime"27.

Tal perspectiva parece-nos muito fecunda para compreender o que se passava também no campo do mobiliário. A almejada utilização de peças industrializadas, tão valorizada pelo discurso modernista internacional, mostrava-se no Brasil uma quimera, a qual foi, no entanto, perseguida pelo arquiteto. Em seu pronunciamento como representante da América do Sul no Congresso de 1931, Warchavchik comentava as dificuldades tecnológicas vivenciadas no Brasil e o quanto essas impactavam a produção dos arquitetos e designers locais:

"Há uma outra dificuldade: não podendo contar com a indústria, precisamos aproveitar a mão de obra. O operário no Brasil, onde se constrói muito e rapidamente, adquire grande habilidade. No entanto, não é fácil formá-lo para o trabalho moderno, e confrontei-me com sérias dificuldades, quando quis organizar os diversos grupos capazes de executar meus projetos. Eu mesmo tive que montar ateliês para que fossem executadas janelas, portas de madeiras lisa, móveis, etc., porque a indústria, que aliás trabalha bastante bem para a arquitetura comum, não pôde realizar o que eu lhe pedia com a precisão e o cuidado necessários" ${ }^{28}$.

Nesse contexto, em nome da unidade formal, o arquiteto abdicava de princípios programáticos e realizava, mesmo que artesanalmente, os elementos compositivos fundamentais para a obtenção de um efeito visual de conjunto harmônico e moderno. De fato, o moderno inseria-se aí a partir das contingências do possível, não como realidade técnica e material, mas como forma pura, como "estilo". A falta de uma indústria e de uma tecnologia desenvolvidas era um empecilho dificilmente contornável para as práticas modernistas, todavia, exemplos como os da Casa da rua Itápolis poderiam sensibilizar aqueles outros sujeitos tão fundamentais para odesenvolvimento da cultura brasileira na direção desse almejado "futuro": os empresários, diversas vezes solicitados nos discursos de Warchavchik, referidos como os novos mecenas da contemporaneidade. Ao comentar os entraves para a execução de casas-tipo no Brasil, que passavam especialmente pela ausência de materiais industrializados adequados, $\mathrm{o}$ arquiteto assinala a importância dos industriais para a sociedade contemporânea:

"[...] Seria, pois, de grande conveniência que os nossos grandes industriais, aos quais cabe o papel dos Medici no século XIV, se interessassem por esse problema, patrocinando as experiências ne- 
cessárias, porque é delas, principalmente, que depende a solução dessa enorme interrogativa, constituída de um assunto técnico e humanitário, concretizada na indústria de casas adequadas ao homem do nosso século"29.

Talvez se possa entender a realização de tal mobiliário, mesmo que permeado de contradições das quais o arquiteto era plenamente consciente, se o tomarmos como um modelo para um futuro desejável, ou seja, um protótipo que poderia sensibilizar as elites industriais nacionais para os rumos de um devir que estava em suas mãos, um devir talvez quimérico, mas com o qual se podia sonhar na São Paulo de finais das décadas de 1920 e 1930.

O mobiliário da Casa Modernista é, assim, revelador das incongruências profundas entre os discursos e utopias modernistas e as práticas históricas concretas com que tais "pioneiros da modernidade" se defrontaram. São a própria materialização das contradições entre a funcionalidade e a plástica propagadas pelo discurso vanguardista internacional e as injunções locais; entre os emblemas de uma civilização industrial simbolizados pelo metal e as condições reais de um país e de uma cidade que se pretendiam modernos, mas sem um desenvolvimento técnico e industrial condizente com seus auspícios; entre a crença na forma e na função racionalistas e a abundância dos materiais orgânicos, essencialmente passadistas, mas pouco custosos. Tais móveis são a materialização da síntese possível entre um discurso internacionalista e uma prática enraizada numa experiência concreta, símbolos dos caminhos tortuosos, incongruentes e contraditórios trilhados, de forma fragmentada e não evolutiva, para a afirmação do modernismo entre nós.

Ana Paula Cavalcanti Simioni é Mestre e Doutora em Sociologia pela USP e docente do Instituto de Estudos Brasileiros da Universidade de São Paulo. 